\title{
Chronic kidney disease linked to SARS-CoV- 2 infection: a case report
}

\author{
Georges Tarris ${ }^{1,2^{*}} \mathbb{D}$, Alexis de Rougemont ${ }^{2}$, Marie-Anaïs Estienney ${ }^{2}$, Julien Journet ${ }^{3}$, Anne-Cécile Lariotte ${ }^{1}$, \\ Damien Aubignat ${ }^{1}$, Jean-Michel Rebibou ${ }^{4}$, Mathilde Funes De La Vega', Mathieu Legendre ${ }^{4}$, Gael Belliot $^{2}$ and \\ Laurent Martin ${ }^{1}$
}

\begin{abstract}
Background: The recent COVID-19 pandemic has raised concerns about patient diagnosis and follow-up of chronically ill patients. Patients suffering from chronic illnesses, concomitantly infected by SARS-CoV-2, globally tend to have a worse prognosis and poor outcomes. Renal tropism and acute kidney injury following SARS-CoV-2 infection has recently been described in the literature, with elevated mortality rates. Furthermore, patients with preexisting chronic kidney disease, infected by SARS-CoV-2, should be monitored carefully. Here, we report the case of a 69-year-old patient with splenic marginal zone lymphoma, suffering from longstanding chronic kidney disease following SARS-CoV-2 infection.
\end{abstract}

Case presentation: A 69-year-old male patient previously diagnosed with pulmonary embolism and splenic marginal zone lymphoma (Splenomegaly, Matutes 2/5, CD5 negative and CD23 positive), was admitted to the hospital with shortness of breath, fever and asthenia. A nasopharyngeal swab test was performed in addition to a CT-scan, which confirmed SARS-CoV-2 infection. Blood creatinine increased following SARS-CoV-2 infection at $130 \mu \mathrm{mol} / \mathrm{l}$, with usual values at $95 \mu \mathrm{mol} / \mathrm{l}$. The patient was discharged at home with rest and symptomatic medical treatment (paracetamol and hydration), then readmitted to the hospital in August 2020. A kidney biopsy was therefore conducted as blood creatinine levels were abnormally elevated. Immunodetection performed in a renal biopsy specimen confirmed co-localization of SARS-CoV2 nucleocapsid and protease 3C proteins with ACE2, Lewis $x$ and sialyl-Lewis $x$ antigens in proximal convoluted tubules and podocytes. Co-localization of structural and nonstructural viral proteins clearly demonstrated viral replication in proximal convoluted tubules in this chronically ill patient. Additionally, we observed the co-localization of sialyl-Lewis $x$ and ACE2 receptors in the same proximal convoluted tubules. Reverse Transcriptase-Polymerase Chain Reaction test performed on the kidney biopsy was negative, with very low Ct levels (above 40). The patient was finally readmitted to the haematology department for initiation of chemotherapy, including CHOP protocol and Rituximab.

\footnotetext{
* Correspondence: georges.tarris@chu-dijon.fr

'Department of Pathology, University Hospital of Dijon, F-21000 Dijon,

France

${ }^{2}$ National Reference Centre for Gastroenteritis Viruses, Laboratory of Virology, University Hospital of Dijon, F-21000 Dijon, France

Full list of author information is available at the end of the article
}

(c) The Author(s). 2021 Open Access This article is licensed under a Creative Commons Attribution 4.0 International License, which permits use, sharing, adaptation, distribution and reproduction in any medium or format, as long as you give appropriate credit to the original author(s) and the source, provide a link to the Creative Commons licence, and indicate if changes were made. The images or other third party material in this article are included in the article's Creative Commons licence, unless indicated otherwise in a credit line to the material. If material is not included in the article's Creative Commons licence and your intended use is not permitted by statutory regulation or exceeds the permitted use, you will need to obtain permission directly from the copyright holder. To view a copy of this licence, visit http://creativecommons.org/licenses/by/4.0/ The Creative Commons Public Domain Dedication waiver (http://creativecommons.org/publicdomain/zero/1.0/) applies to the data made available in this article, unless otherwise stated in a credit line to the data. 
Conclusions: Our case emphasizes on the importance of monitoring kidney function in immunosuppressed patients and patients suffering from cancer following SARS-CoV-2 infection, through histological screening. Further studies will be required to decipher the mechanisms underlying chronic kidney disease and the putative role of sialyl-Lewis $x$ and HBGA during SARS-COV-2 infection.

Keywords: Coronavirus, COVID-19, SARS-CoV-2, Chronic viral replication, Chronic kidney disease, Immunocompromised, HBGA, Lewis antigens, Case report

\section{Background}

Since December 2019, the COVID-19 pandemic has become a major public health issue worldwide and the source of substantial healthcare costs [1]. Severe Acute Respiratory Syndrome related Coronavirus-2 (SARS$\mathrm{CoV}-2$ ) belongs to the Sarbecovirus subgenus along with Severe Acute Respiratory Syndrome related Coronavirus-1 (SARS-CoV-1) [2]. SARS-CoV-2 possesses a large spectrum of virulence, varying from asymptomatic infection to severe acute respiratory syndrome (SARS) and multi-organ failure linked to cytokine storm, with possible Kawasaki-like syndromes and autoimmune manifestations, linked to interleukin 6 (IL-6) hypersecretion [3, 4]. Autopsy case series have shown several types of lesions linked to SARS-CoV-2 infection, especially alveolar damage with viral replication in pneumocytes, but also viral replication in the kidneys with podocyte and proximal tubular involvement $[5,6]$. Acute kidney injury has also been associated with severe COVID-19 infection and increased in-hospital mortality [7]. SARS-CoV-2 mainly uses the angiotensin-converting enzyme (ACE2) as an entry point into infected cells prior to protein priming by transmembrane protease serine 2 (TMPRSS2) [8]. Blood group antigen polymorphisms might also modulate virus binding and infectivity, as individuals with blood group $\mathrm{A}$ and $\mathrm{B}$ are potentially more susceptible to SARS-CoV-2 infections $[9,10]$. Epidemiological studies recently illustrated the association between SARS-CoV-2 severe renal dysfunction and the occurrence of chronic comorbidities [11]. Here, we demonstrate the occurrence of SARS-CoV-2 chronic replication in the kidney of a comorbid patient, leading to longstanding chronic kidney disease (CKD).

\section{Case presentation}

In April 2020, a 69-year-old man with blood group A was admitted to the William-Morey General Hospital (Chalon-sur-Saône, France), with shortness of breath, fever and fatigue. His personal medical history included an indolent splenic marginal zone lymphoma (SMZL) of Matutes score 2 (splenomegaly, CD5 negativity and CD23 positivity), diagnosed following an idiopathic pulmonary embolism in December 2019, with no previous history of lung disease [12]. The patient was initially treated with apixaban for his pulmonary embolism. At the emergency room, a thoracic CT-scan showed bilateral ground-glass pulmonary infiltrates suggesting SARS-CoV-2 infection which was later confirmed by a nasopharyngeal swab RT-qPCR test. Blood tests showed elevated blood C-reactive protein $(25 \mathrm{mg} / \mathrm{ml})$ and ferritin $(514 \mathrm{ng} / \mathrm{dl})$ levels, associated with a deep lymphopenia $(0,03 \mathrm{G} / \mathrm{L})$, but normal electrolytes, urea and creatinine levels. The patient was carefully monitored and his condition rapidly improved with appropriate hydration and ventilation. One week later, the patient was discharged at home with routine guidelines following SARS-CoV-2 infection, including rest at home, hand hygiene, avoidance of contact with the surroundings, paracetamol intake and appropriate hydration in case of symptoms. During the following weeks, the patient suffered from dyspnea at exertion and chronic invalidating fatigue at home, later confirmed by his family physician. Serologies for SARS-CoV-2 performed in June 2020 were negative.

In August 2020, the patient was again admitted to the hospital due to intense exhaustion and significant weight loss $(6 \mathrm{~kg})$ during the 2 weeks prior to his admission, associated with mild fever, breathlessness and daytime sweating. Laboratory tests showed a microcytic anaemia $(10.5 \mathrm{~g} / \mathrm{dl})$, a mild hypogammaglobulinemia associated with a persistent lymphopenia $(0.6 \mathrm{G} / \mathrm{L})$ and an altered renal function with elevated serum creatinine $(167 \mu \mathrm{mol} /$ l) and urea levels $(13.7 \mathrm{mmol} / \mathrm{l})$. The estimated glomerular filtration rate (eGFR) was $35 \mathrm{ml} / \mathrm{min} / 1.73 \mathrm{~m}^{2}$ using the CKD-EPI formula. Urine analysis revealed mild proteinuria at $0.09 \mathrm{~g} / 24 \mathrm{~h}$.

A kidney biopsy was then performed to explore the chronic kidney disease and sent to the Pathology Department of the University Hospital of Dijon (Bourgogne, France) for further investigation. Analysis of the kidney biopsy was conducted according to previously established criteria [13]. Histopathology showed 9 normal glomeruli and 2 obsolescent glomeruli with cortical grade I fibrosis and grade I tubular atrophy with focal interstitial inflammation, focal sloughing of epithelial cells of proximal convoluted tubules and intra-tubular cell casts, which indicated reversible and focal tubular necrosis (Fig. 1A and B). Periodic Acid Schiff (PAS) staining revealed desquamation of the brush border of proximal convoluted tubules (Fig. 1B). Silver impregnation (Marinozzi) showed otherwise normal glomerular 


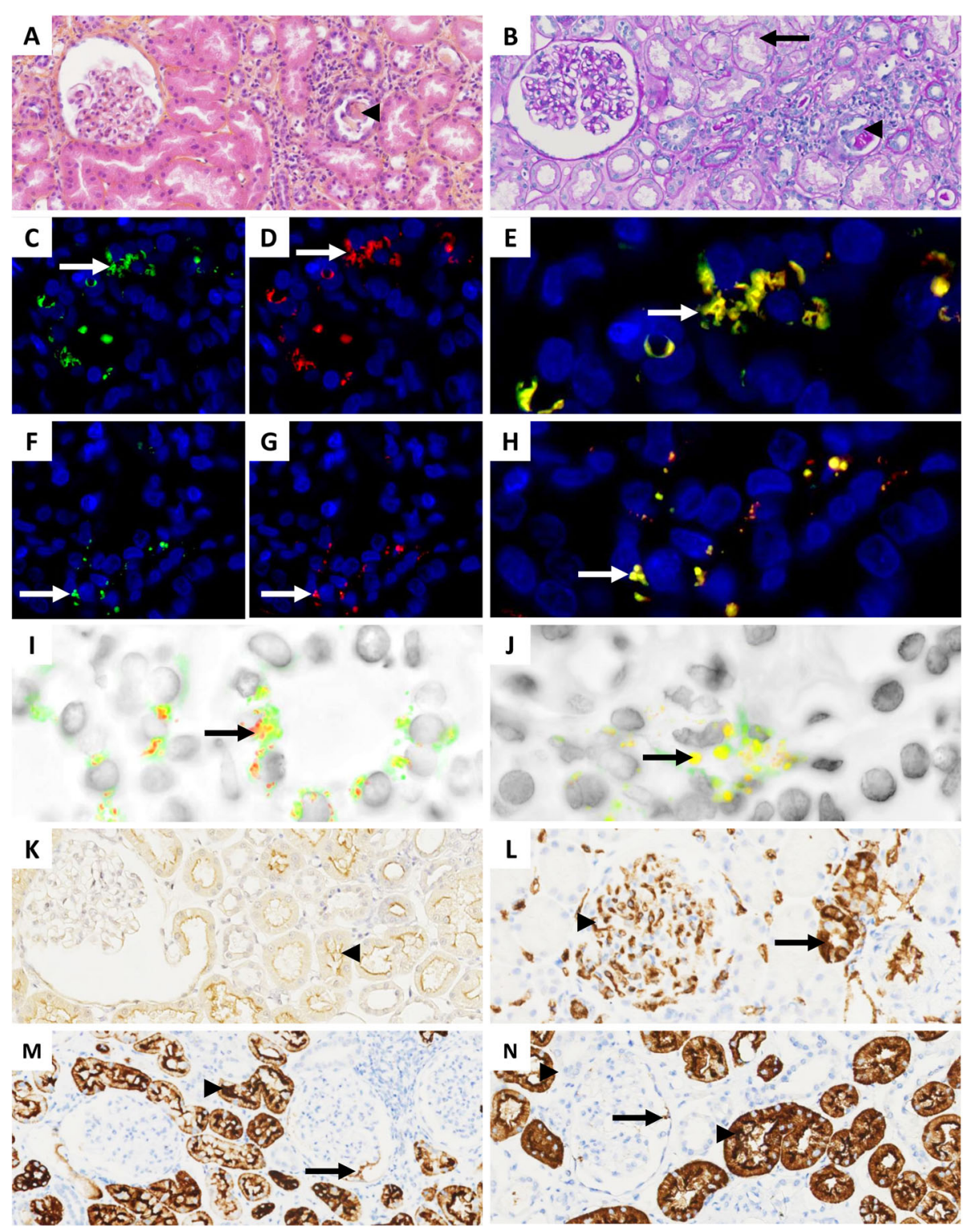

Fig. 1 Histopathology and immunodetection assays in formalin-fixed paraffin embedded kidney biopsy from a 69-year-old patient suffering from chronic COVID-19 infection. A (HES, × 200) and B (PAS, × 200): grade I interstitial fibrosis associated with grade I tubular atrophy without glomerular damage; focal desquamation of the brush border of epithelial cells of proximal convoluted tubules (arrow), associated with focal sloughing of epithelial cells of proximal convoluted tubules with intra-tubular cell casts (arrowheads); C, D, E and I ( $\times 600$ ): co-detection of SARSCoV-2 nucleoprotein (green fluorescence) and protease-3C (red fluorescence) in epithelial cells of proximal convoluted tubules (arrows) using anti-NP and anti-Prot3C mAb; F, G, H and $\mathbf{J}(\times 600)$ : co-detection of SARS-CoV-2 nucleoprotein (green fluorescence) and protease3C (red fluorescence) in the glomerular apparatus (arrows) using anti-NP and anti-Prot3C mAb; $\mathbf{K}(\times 200)$ : ACE2 detection on the brush border of epithelial cells of proximal convoluted tubules (arrowhead) using anti-ACE2 mAb. Positive detection is shown by brown staining; $\mathbf{L}(\times 200)$ : A antigen expression in glomerular capillary walls (arrowhead) and distal convoluted tubules (arrow) using anti-A mAb. Positive detection is shown by brown staining; $\mathbf{M}(\times 200)$ : Le $\mathrm{e}^{\mathrm{x}}$ antigen expression in proximal convoluted tubules (arrowhead) and podocytes (arrow) using anti-Le $\mathrm{mAb}$. Positive detection is shown by brown staining; $\mathbf{N}(\times 200)$ : sialyl-Le ${ }^{x}$ antigen expression in proximal convoluted tubules (arrowhead) and podocytes (arrow). Positive detection is shown by brown staining

basement membranes. Congo red staining and direct immunofluorescence for IgA, IgM, IgG, albumin, fibrinogen, C3, C4c, C1q, kappa and lambda light chains were all negative.
The presence of focal tubular necrosis was initially attributed to possible dehydration in a patient which manifested daytime sweating, as clinical examination and history taking ruled out other causes of tubular injury. 
In the context of tubular lesions in a patient suffering from symptom exacerbation possibly related to SARSCoV-2 infection, the possibility of direct tubular damage due to SARS-CoV-2 replication was explored through SARS-CoV-2 immunohistological analysis on biopsy slides following described protocols (Supplemental data). Double fluorescent staining revealed cytoplasmic colocalization of SARS-CoV-2 nucleoprotein and protease$3 \mathrm{C}$ in proximal convoluted tubules and podocytes, demonstrating virus binding and replication (Figs. 1C -J). Immunohistochemistry demonstrated the expression of ACE2 in the cytoplasm of epithelial cells bordering the proximal convoluted tubules (Fig. 1K), A antigen in capillary walls and distal convoluted tubules (Fig. 1L), and $\mathrm{Le}^{\mathrm{x}}$ and sialyl-Le ${ }^{\mathrm{x}}(\mathrm{CD} 15 \mathrm{~s})$ in the proximal convoluted tubules and podocytes (Fig. $1 \mathrm{M}$ and $\mathrm{N}$ ).

The patient received effective and complete anticoagulative therapy by apixaban from December 2019 to April 2020. The patient stayed at the hospital for one week, with intravenous fluids and careful monitoring until his renal function improved enough to be sent home with appropriate symptomatic care. At present, the patient continues to complain of persistent dyspnoea on exertion and chronic fatigue, possibly caused by aggravation of SMZL or persistent SARS-CoV-2 infection. The patient was later readmitted to the haematology department for initiation of chemotherapy including Cyclophosphamide, Hydroxydaunorubicin, Oncovin and Prednisone (CHOP), without administration of Rituximab due to chronic kidney disease partially induced by the previous SARS-CoV-2 infection. Testing of SARS$\mathrm{CoV}-2$ using serologies and nasopharyngeal swabs were negative in January 2021.
Before the initial episode of infection, blood creatinine levels were estimated at $95 \mu \mathrm{mol} / \mathrm{l}$ (eGFR was initially measured at $72 \mathrm{ml} / \mathrm{min} / 1.73 \mathrm{~m}^{2}$ ). Blood creatinine levels increased to $130 \mu \mathrm{mol} / \mathrm{l}$ in April 2020 (eGFR: $50 \mathrm{ml} / \mathrm{min} /$ $1.73 \mathrm{~m}^{2}$ ) up to $230 \mu \mathrm{mol} / \mathrm{l}$ in August 2020 (eGFR: $26 \mathrm{ml} /$ $\mathrm{min} / 1.73 \mathrm{~m}^{2}$ ). Thereafter, the renal function was sustainably altered, with blood creatinine values ranging from 120 to $180 \mu \mathrm{mol} / \mathrm{l}$ (eGFR from 35 to $55 \mathrm{ml} / \mathrm{min} / 1.73 \mathrm{~m}^{2}$ ) (Fig. 2). Of note, no measurements of renal function were conducted between April 2020 and August 2020.

\section{Discussion and conclusions}

Based on autopsy tissue samples, the ability of SARS$\mathrm{CoV} 2$ to bind, replicate and induce cellular damage in podocytes and proximal convoluted tubules, where ACE2 is highly expressed, have been suggested $[5,6]$. Recent data has described the mechanisms underlying SARS-CoV-2 replication and kidney damage involving innate immunity and coagulation pathways $[14,15]$. Indeed, SARS-CoV-2 binding to ACE2 induces CD4+ and CD8+ lymphocyte depletion as seen in our case, in addition to the SMZL comorbidity in this patient, that might have aggravated lymphocyte depletion [16]. Moreover, elevated ferritin levels and anaemia could reflect chronic inflammation linked to SARS-CoV-2 infection, and could be used as a marker of persistent infection $[17,18]$. The expression of histo-blood group antigens (HBGA) in nephrons could also contribute to SARSCoV-2 binding, as $\mathrm{Le}^{\mathrm{x}}$ and CD15s are highly expressed in proximal convoluted tubules [19]. Indeed, in vitro studies have shown the high affinity of SARS-CoV-2 spike glycoprotein towards CD15s and other sialylated molecules with differential ligand affinity, as described

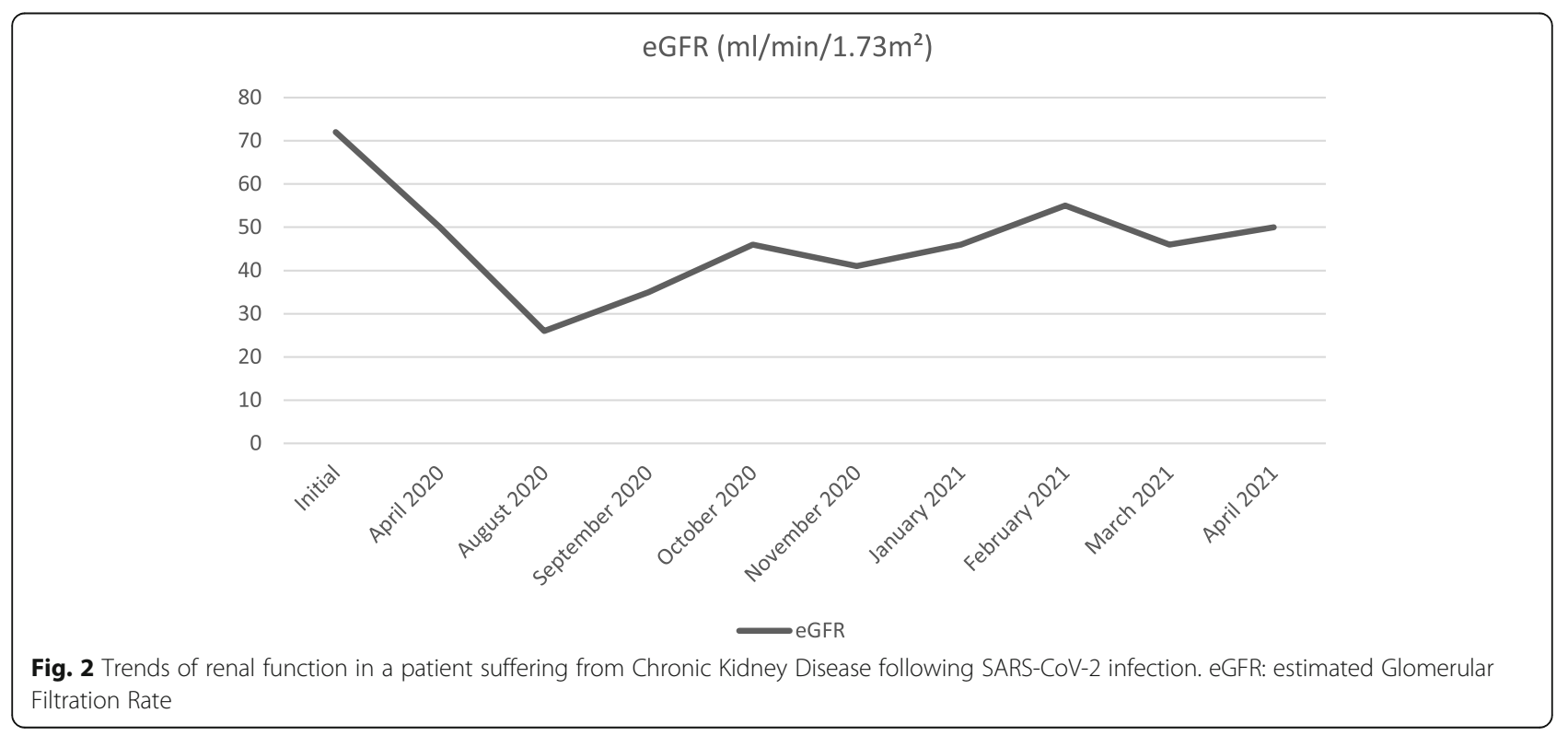


with MERS-CoV and SARS-CoV-1 [20]. Additionally, the role of the blood group A antigen in SARS-CoV-2 susceptibility was not highlighted in our case, as its identification in capillary walls and distal convoluted tubules was not related to SARS-CoV-2 binding and replication $[10,19,21]$.

Further studies will be required in order to understand the mechanisms underlying chronic kidney disease associated with SARS-CoV-2 binding and replication in kidney cells. Kemp et al. recently described the possibility of SARS-CoV-2 to chronically infect a 70-year-old patient suffering from B-cell lymphoma, and to replicate in organs with possible de novo mutations of the spike protein at different sites of replication [22]. Regarding the occurrence of renal damage linked to SARS-CoV-2 infections, the high incidence of acute kidney injury (AKI) and acute tubular necrosis with SARS-CoV-2 replication in proximal convoluted tubules in severe and lethal forms of SARS-CoV-2 infections has previously been documented in the literature [23]. Actual scientific data points towards CKD as an important risk factor of severe and prolonged SARS-CoV-2 infection [11, $24,25]$. To our knowledge, data concerning the mechanisms underlying the occurrence of CKD following SARS-CoV-2 infection remain scarce. Current guidelines raise concern about appropriate surveillance of kidney function in patients who suffered from SARS-CoV-2 infection, indicating to refer patients with symptoms of exacerbation of chronic kidney disease or heavy proteinuria, and regular blood and urine analyses [26, 27]. The importance of histological screening in patients with CKD following SARS-CoV-2 infection remain an important point to discuss in comorbid patients recovering from SARS$\mathrm{CoV}-2$ infection. Until vaccination becomes fully developed worldwide, more complete data will be needed in order to provide appropriate care and treatment for comorbid patients suffering from chronic kidney disease following SARS-CoV-2 infection.

\section{Abbreviations}

ACE2: Angiotensin-Converting Enzyme 2; AKI: Acute Kidney Injury; C1q: Complement component 1q; C3: Complement component 3; C4c: Complement component 4; Ct: Cycle threshold; CT-scan: ComputedTomography scan; CD15s: Sialyl-lewis x; CD4: Cluster of Differentiation 4; CD5: Cluster of Differentiation 5; CD23: Cluster of Differentiation 23; CD8: Cluster of Differentiation 8; CKD: Chronic Kidney Disease; CKDEPI: Chronic Kidney Diseases - Epidemiology Collaboration; COVID19: Coronavirus Disease of 2019; eGFR: Estimated Glomerular Filtration Rate; HBGA: Histo-Blood Group Antigens; IgA: Immunoglobulin A; IgG : Immunoglobulin G; IgM : Immunoglobulin M; IL-6 : Interleukin 6; IL8: Interleukin 8; Lex: Lewis x; mAb: Monoclonal antibody; MERS-CoV: Middle East Respiratory Syndrome - Coronavirus; PAS: Periodic Acid Schiff; SARS-CoV1: Severe Acute Respiratory Syndrome - Coronavirus 1; SARS-CoV-2: Severe Acute Respiratory Syndrome - Coronavirus 2; SMZL: Splenic Marginal Zone Lymphoma; TMPRSS2: Transmembrane Protease Serine 2

\section{Supplementary Information}

The online version contains supplementary material available at https://doi. org/10.1186/s12882-021-02490-z.

\section{Additional file 1}

\section{Acknowledgements}

not applicable.

\section{Authors' contributions}

Conceptualization.

GT, GB, LM; Methodology: GT, GB; Investigation: GT, AdR, DA, MAE, ACL, MFDLV, GB; Resources: AdR, DA, MAE, JJ, JMR, ML, GB, LM; Validation: GB, LM; Writing original draft: GT, GB; Writing review \& editing: GT, AdR, GB, LM; Funding acquisition: AdR, GB, LM; all authors read and approved the final manuscript.

\section{Funding}

fundings were provided by Santé Publique France (SPF) and Fonds Européen de DEveloppement Régional (FEDER) \#IGDA 2017-6200FEO001S01850. This funding has contributed to the purchase of the antibodies and reagents used in this case report.

\section{Availability of data and materials}

The images and digitized histology analysed during the current study are available from the corresponding author on reasonable request.

\section{Declarations}

Ethics approval and consent to participate not applicable.

\section{Consent for publication}

Written informed consent was obtained from the patient for publication of this case report and any accompanying images. A copy of the written consent is available for review by the Editor of this journal.

\section{Competing interests}

The authors declare that they have no competing interests.

\section{Author details}

'Department of Pathology, University Hospital of Dijon, F-21000 Dijon, France. ${ }^{2}$ National Reference Centre for Gastroenteritis Viruses, Laboratory of Virology, University Hospital of Dijon, F-21000 Dijon, France. ${ }^{3}$ Department of Nephrology, William Morey Hospital, F-71100 Chalon-sur-Saône, France. ${ }^{4}$ Department of Nephrology, University Hospital of Dijon, F-21000 Dijon, France.

Received: 1 April 2021 Accepted: 2 August 2021

Published online: 10 August 2021

\section{References}

1. Zhu H, Wei L, Niu P. The novel coronavirus outbreak in Wuhan, China. Glob Health Res Policy. 2020;5:6. https://doi.org/10.1186/s41256-020-00135-6.

2. Coronaviridae Study Group of the International Committee on Taxonomy of Viruses. The species severe acute respiratory syndrome-related coronavirus: classifying 2019-nCoV and naming it SARS-CoV-2. Nat Microbiol. 2020;5(4): 536-44. https://doi.org/10.1038/s41564-020-0695-z.

3. Tang Y, Liu J, Zhang D, Xu Z, Ji J, Wen C. Cytokine storm in COVID-19: the current evidence and treatment strategies. Front Immunol. 2020;11:1708. https://doi.org/10.3389/fimmu.2020.01708.

4. Long Q-X, Tang X-J, Shi Q-L, Li Q, Deng H-J, Yuan J, et al. Clinical and immunological assessment of asymptomatic SARS-CoV-2 infections. Nat Med. 2020;26(8):1200-4. https://doi.org/10.1038/s41591-020-0965-6.

5. Puelles VG, Lütgehetmann M, Lindenmeyer MT, Sperhake JP, Wong MN, Allweiss $L$, et al. Multiorgan and renal tropism of SARS-CoV-2. N Engl J Med. 2020;383(6):590-2. https://doi.org/10.1056/NEJMc2011400.

6. Su H, Yang M, Wan C, Yi L-X, Tang F, Zhu H-Y, et al. Renal histopathological analysis of 26 postmortem findings of patients with COVID-19 in China. Kidney Int. 2020;98(1):219-27. https://doi.org/10.1016/j.kint.2020.04.003. 
7. Cheng Y, Luo R, Wang K, Zhang M, Wang Z, Dong L, et al. Kidney disease is associated with in-hospital death of patients with COVID-19. Kidney Int. 2020;97(5):829-38. https://doi.org/10.1016/j.kint.2020.03.005.

8. Shang J, Wan Y, Luo C, Ye G, Geng Q, Auerbach A, et al. Cell entry mechanisms of SARS-CoV-2. Proc Natl Acad Sci U S A. 2020;117(21):1172734. https://doi.org/10.1073/pnas.2003138117.

9. Yamamoto F, Yamamoto M, Muñiz-Diaz E. Blood group ABO polymorphism inhibits SARS-CoV-2 infection and affects COVID-19 progression. Vox Sang. 2021;116(1):15-7. https://doi.org/10.1111/vox.13004.

10. Breiman A, Ruvën-Clouet N, Le Pendu J. Harnessing the natural anti-glycan immune response to limit the transmission of enveloped viruses such as SARS-CoV-2. PLoS Pathog. 2020;16(5):e1008556. https://doi.org/10.1371/ journal.ppat.1008556.

11. Guan W-J, Liang W-H, Zhao Y, Liang H-R, Chen Z-S, Li Y-M, et al. Comorbidity and its impact on 1590 patients with COVID-19 in China: a nationwide analysis. Eur Respir J. 2020;55(5):2000547. https://doi.org/10.11 83/13993003.00547-2020.

12. Matutes E. Splenic marginal zone lymphoma: disease features and management. Expert Rev Hematol. 2013;6(6):735-45. https://doi.org/10.1 586/17474086.2013.845522.

13. Walker PD, Cavallo T, Bonsib SM, Ad Hoc Committee on Renal Biopsy Guidelines of the Renal Pathology Society. Practice guidelines for the renal biopsy. Mod Pathol. 2004;17(12):1555-63. https://doi.org/10.1038/modpa thol.3800239.

14. Chen G, Wu D, Guo W, Cao Y, Huang D, Wang H, et al. Clinical and immunological features of severe and moderate coronavirus disease 2019. J Clin Invest. 2020;130(5):2620-9. https://doi.org/10.1172/JCl137244.

15. Giannis D, Ziogas IA, Gianni P. Coagulation disorders in coronavirus infected patients: COVID-19, SARS-CoV-1, MERS-CoV and lessons from the past. J Clin Virol. 2020;127:104362

16. Arcaini L, Rossi D, Paulli M. Splenic marginal zone lymphoma: from genetics to management. Blood. 2016;127(17):2072-81. https://doi.org/10.1182/ blood-2015-11-624312.

17. Kappert K, Jahić A, Tauber R. Assessment of serum ferritin as a biomarker in COVID-19: bystander or participant? Insights by comparison with other infectious and non-infectious diseases. Biomarkers. 2020;25(8):616-25. https://doi.org/10.1080/1354750X.2020.1797880.

18. Perricone C, Bartoloni E, Bursi R, Cafaro G, Guidelli GM, Shoenfeld Y, et al. COVID-19 as part of the hyperferritinemic syndromes: the role of iron depletion therapy. Immunol Res. 2020;68(4):213-24. https://doi.org/10.1007/ s12026-020-09145-5.

19. Ravn V, Dabelsteen E. Tissue distribution of histo-blood group antigens. APMIS Acta Pathol Microbiol Immunol Scand. 2000;108(1):1-28. https://doi. org/10.1034/j.1600-0463.2000.d01-1.x.

20. Awasthi M, Gulati S, Sarkar DP, Tiwari S, Kateriya S, Ranjan P, et al. The Sialoside-binding pocket of SARS-CoV-2 spike glycoprotein structurally resembles MERS-CoV. Viruses. 2020;12(9). https://doi.org/10.3390/v12090909.

21. Golinelli $D$, Boetto $E$, Maietti E, Fantini MP. The association between $A B O$ blood group and SARS-CoV-2 infection: a meta-analysis. PLoS One. 2020 15(9):e0239508. https://doi.org/10.1371/journal.pone.0239508.

22. Kemp SA, Collier DA, Datir RP, Ferreira IATM, Gayed S, Jahun A, et al. SARSCoV-2 evolution during treatment of chronic infection. Nature. 2021; 592(7853):277-82. https://doi.org/10.1038/s41586-021-03291-y.

23. Diao B, Wang C, Wang R, Feng Z, Zhang J, Yang $\mathrm{H}$, et al. Human kidney is a target for novel severe acute respiratory syndrome coronavirus 2 infection. Nat Commun. 2021;12(1):2506. https://doi.org/10.1038/s41467-021-22781-1.

24. O'Sullivan ED, Lees JS, Howie KL, Pugh D, Gillis KA, Traynor JP, et al. Prolonged SARS-CoV-2 viral shedding in patients with chronic kidney disease. Nephrol Carlton Vic. 2021;26(4):328-32. https://doi.org/10.1111/ nep.13844.

25. ERA-EDTA Council. ERACODA working group. Chronic kidney disease is a key risk factor for severe COVID-19: a call to action by the ERA-EDTA. Nephrol Dial Transplant. 2021;36(1):87-94. https://doi.org/10.1093/ndt/ gfaa314.

26. COVID-19 rapid guideline: chronic kidney disease. London: National Institute for Health and Care Excellence (UK); 2020 May 15. (NICE Guideline, No. 176.)

27. Kant S, Menez SP, Hanouneh M, Fine DM, Crews DC, Brennan DC, et al. The COVID-19 nephrology compendium: AKI, CKD, ESKD and transplantation. BMC Nephrol. 2020;21(1):449. https://doi.org/10.1186/s12882-020-02112-0.

\section{Publisher's Note}

Springer Nature remains neutral with regard to jurisdictional claims in published maps and institutional affiliations.

\section{Ready to submit your research? Choose BMC and benefit from:}

- fast, convenient online submission

- thorough peer review by experienced researchers in your field

- rapid publication on acceptance

- support for research data, including large and complex data types

- gold Open Access which fosters wider collaboration and increased citations

- maximum visibility for your research: over $100 \mathrm{M}$ website views per year

At BMC, research is always in progress.

Learn more biomedcentral.com/submissions 